\title{
Puducherry Before the Age of Indo-Roman (Pre-Periplus) Trade Phase
}

\author{
P. Ravitchandirane* \\ Assistant Professor of History, Tagore Arts College, Puducherry; perravi0805@gmail.com
}

\begin{abstract}
The results of early excavations are promoted to conclude that the site Arikamedu was a base on Indian east coast for Roman maritime trade during early current era. The question on pre-urban phase at Arikamedu which lead to the Periplus trade is yet to be known. The pre-periplus or the proto historic of Puducherry is almost the beginning stage of urban development. The proto historic age of Puducherry seems that it began with the Iron Age which is popularly known to the scholars as megaliths. The available evidence suggests that the Iron Age of Puducherry seems largely to have been restricted to burials. Many hundreds of Urn burials were unearthed either unknowingly or systematically. The systematic excavations were carried out at Souttoukeny and Mouttrapaleon by Casals in 1950s. The early one was with Cist burials and the later one was Urn burials. Very recently nearly fifty Iron Age burials of Urn and Cist types were excavated at Auroville by the author. In addition to this, the materials brought form the accidental discoveries are put together as sources for the study to understand the prehabitation of Indo-Roman trade phase (pre-periplus) and ancient urbanization at Arikamedu in Puducherry.
\end{abstract}

Keywords: Cairn Circle, Lateritic, Megalithic, Neo-Chalcolithic, Neolithic, Periplus, Sarcophagus

\section{Early Notions on Pre-Periplus Phase}

Though the Neolithic type tools largely found in the Puducherry region, none of them have connection with the pure Neolithic settlement in Puducherry. The term chalcolithic was used by Casal on the collections of Fr. Faucheux ${ }^{1}$. Casal roughly identified some of Fr. Faucheux collections from Gorimedu and Mangalam as Neo-Chalcolithi type. Leshnik L. S., points out, some artefacts - such as the bronze bracelet with trumpet ends from Gorimedu-have parallels in the Iron Age graves ${ }^{2}$.

Neolithic type polished stone tools (Figure 1) have been found on the surface and in the excavations of Iron Agecemetery sites like Perimbe ${ }^{3}$ and Auroville ${ }^{4}$ and habitation site Arikamedu ${ }^{5}$. These findings are very difficult to equate with neither Neolithic nor Neo-Chalcolithic cultures. Previous researchers like Casals chronology is however, uncertain, since they identified only two sites such as Gorimedu and Mangalam as Neo-Chalcolithic were not in their excavations ${ }^{6}$.

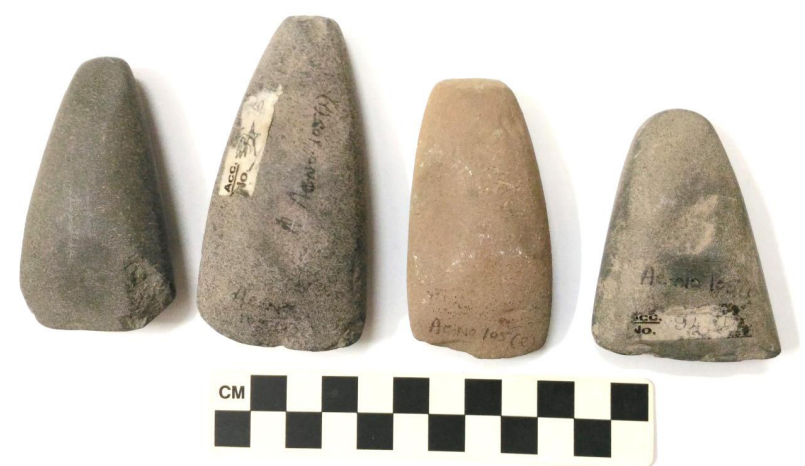

Figure 1. Neolithic Type Tools Found In and Around Arikamedu, Now in Pondicherry Museum.

In addition, the materials that they used to name the Neo-Chalcolithic age are neither being in Pondicherry

${ }^{*}$ Author for correspondence 
Museum nor in the school which they mentioned. Moreover, no such Chalcolithic settlement or burials sites other than Gorimedu and Mangalam have been discovered since Casals.

\section{The Proto Historic Phase}

The proto history of Puducherry began with the Iron Age or the so called megaliths. Based on M. G. JouveauDubreuilstudies, P. Z. Pattabiramin published a list of ancient sites in Puducherry region ${ }^{7}$, which are mostly Iron Age burials and a few medieval period sites. Before independence hundreds of Iron Age burials had been discovered in the Puducherry area and some of them were excavated by some European scholars like Laffitte and Casal. Since independence the excavations were conducted by the Archaeological Survey of India at Sathamangalam in $1983^{8}$, and at Auroville in $1986^{\circ}$. Due to various reasons no detailed reports till date could be brought out. However, a preliminary report on Auroville Iron Age burials has been brought out by Mr. Poppo Pingel who has founded the Auroville Museum for Archaeology ${ }^{10}$.

\section{The Location and Types of Iron Age Burials}

The distribution of Iron Age cemetery sites in Puducherry and its immediate vicinity shows that most of the burials were made mainly on the northern area of the Gingee river, with sporadic occurrences on lateritic red clay gravel of raised moor lands, even though a few cemetery sites have been discovered on the southern area of Gingee river.

The significance of Iron Age graves is usually found along the northern plains of the Gingee river, on eminencies and slopes of lateritic red soil lands. Commonly, the Urns are placed in pits cut in to red soil, occasionally marked with stone circle. Less often, sarcophagus (Figure 2) has been placed in a swastika pattern of granite slab Cist in a huge pit. However, these Cist burials usually marked with stone circle on the surface (Figure 3 ). These types of burials are normally found in the vicinity of Thiruvakkarai and Suttukeni at the west and Auroville at the north of Puducherry.

The next frequency of Urn burials extend at Perimbe and Muthrapaleaon. These are mostly Urn burials which are found with or without any surface markings. Occasionally at Sengamedu, these burials were marked without stone circles. Moreover, the Urn burials are also found along with Auroville, Sengamedu and Thiruvakkarai Cist burials.

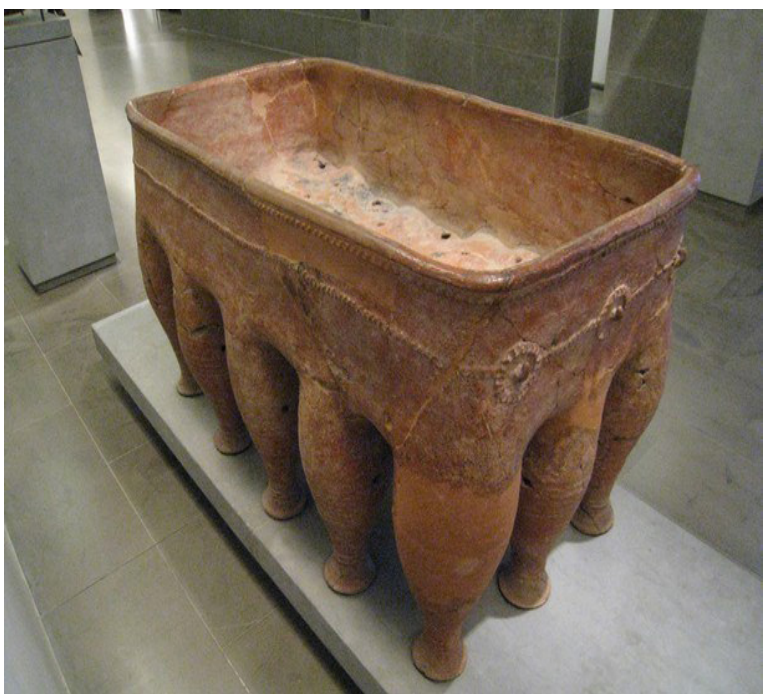

Figure 2. Sarcophagus from Suttukeni Burials Excavated by Casal, now in France.

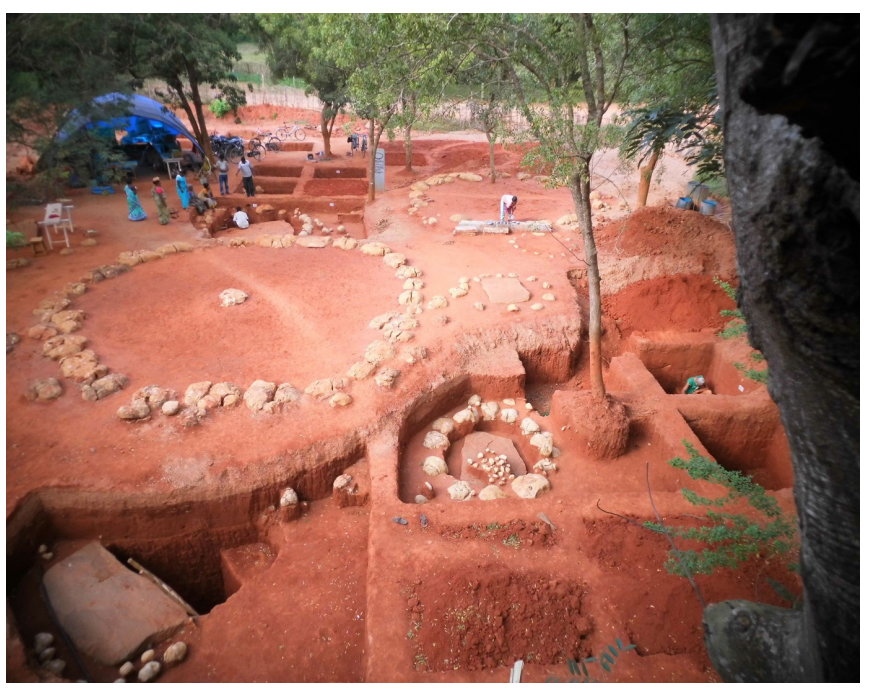

Figure 3. Iron Age Burials Marked with Stone (Auroville).

Apart from these areas, Urn burials have been identified in alluvial deposits in the southern plains of the Gingee river such as Puranang kuppam ${ }^{11}$ and an Urn was identified and dug out at Bahour by Kuppuswamy ${ }^{12}$. Very recently one Urn was unearthed near Arikamedu and now in Pondicherry Museum. The unfortunate is that none of burial urns from this alluvial deposit have the grave goods.

\section{Pre-Periplus Trade Phase of Arikamedu}

From the beginning Arikamedu was documented as ancient sea port which developed with foreign influences. The fragments of Roman table ware and shipping 
jars found thought out the deposits of Arikamedu made Wheeler to believe that Arikamedu was an ancient sea-port established in 1st century BCE and declined peacefully in $2^{\text {nd }}$ century CE. Perhaps, Arikamedu is the most important proto-and-early historical site, not only in the territory of Puducherry but in south India. For it has provided date for fixing period of south Indian Archaeological sequence, as well as evidence for trade direct and indirect, with Mediterranean region from ca. early second century BCE to the end of fifth century $\mathrm{CE}^{13}$.

This port has been often linked to the 'Poduke Emporium' of classical writers ${ }^{14}$. In 1947, J. M. Casal found megalithic pottery in the early level deposits at southern part of Arikamedu, for he was hoping that the sea people who had the contacts with the Hellenistic and the Romans of Mediterranean in the early times. The identification of Black and Red ware (megalithic pottery) at the early levels of Arikamedu made Casal to open the pre-periplus trade phase with Iron Age fishing hamlets, popularly known as Megalithic culture ${ }^{15}$.

\subsection{Fishing Hamlets}

The earliest habitation of Arikamedu pre-dates the beginning of any known overseas trade and it also pre-dates the use of 'rouletted ware' at the site ${ }^{16}$. The early settlement is identified primarily on the basis of its megalithic pottery. Casal had a conclusion that the earliest occupation was occurred in the Megalithic period because of the pottery which he observed, had similarities to pottery at "megalithic" sites. He assumed that Arikamedu early habitation was a fishing sea people who used black and red ware. He found there are no remains of "megalithic" or burials of any kind at Arikamedu. In addition, in the early level there area few post-holes and no indications of brick used building activities ${ }^{17}$. Not much else is known about this early level and it was considered a small settlement, probably of fishermen ${ }^{18}$, as he assumed after his excavations in 1947. He stated that Arikamedu was first inhabited by fisher men who used megalithic pottery. His assumption was that sea fishing people at southern Arikamedu came imposing western ships traders who later settled in the northern part of the site.

After Casal excavations, Wheeler slightly changed his concept on Arikamedu. In his later publication Wheeler suggests that the fishing village of Arikamedu made contact with the (Indian) traders who arrived from the west coast of India bringing Mediterranean commodities. They established a small foreign quarter at the northern part of
Arikamedu, and finally the village was replaced by a brick built town ${ }^{19}$.

The present occupations at the modern villages around Arikamedu mound are fishing and toddy making. This could not be equated with $3^{\text {rd }}$ century BCE occupation. Fishing may be considered as a major occupation to the people who residing on the coast, but the early habitation of Arikamedu, on the basis of materials like beads from the excavations seem very difficult to conclude that the fishing community was the early settlement with whom the western traders made trade. In addition, prior to the IndoRoman trade phase is now identified as Iron Age people on basis the Iron Age pottery and absence of any related fishing occupation.

\section{Iron Age (Megalithic) Culture in Puducherry}

The first settlers of Puducherry who have known the use of iron and inverted firing technology (black-and-red ware) were possibly migrated from the modern neighboring state of this territory between $300 \mathrm{BCE}$ and $500 \mathrm{BCE}^{20}$. It is uncertain whether the migration was through the land or sea or both ways. But it could be concluded that a mass Iron Age people migrated to Puducherry area and settled at various regions. One group arrived possible at the end of the $3^{\text {rd }}$ or early $2^{\text {nd }}$ century BCE established habitation at the south end of the eastern bank of the northern outlet of the river Gingee, just before it enters the Bay of Bengal. This group made the Industrial activities like bead making, shell cutting and metal works. They possibly imported the raw materials from various center of South India. Settlement was being very close to the sea might be very easy to bring the materials like stone and metal ore to manufacture beads, copper objects and Iron implements.

\subsection{Iron Age Burials Types and Cultural Patterns}

In 1950, Casal J. M. interested in pre-Periplus time of Arikamedu, Casal J. M. and G Casal further surveyed in the Puducherry area and excavated two Iron Age burial sites -Suttukeni and Muthrapalea on that are located along the river Gingee.

Suttukeni burials were first identified and excavation was carried in 1950 by Casal G and Pierre Antoine under the direction of Casal J. M. Since Casal, Suttukeni has been recognized as the most important Iron Age burial site in 
the south India, not only for Iron Age culture but also on the preceding culture of Classical trade phase in the early current era of Arikamedu and its contemporary sites. Until recent years no further study has been taken on his report or a new approach on his excavated materials. Casal group found two sarcophagi in a cist.

Suttukeni sarcophagi pit was filled with a deposit of non-local red sand ${ }^{21}$. This type of non-local red sand fillings is noticed in the sections of Urns which are in our recent study at Auroville, Perimbe, Sengamedu and Thiruvakkarai burials. Casals also described the filling of non-local red sand fillings in Muthrapaleaon burials. Either Casal or by us is very difficult to trace out the sources of non-local red sand. It is possibly sewed sand were from river bed or canyon red sand. It might turn to red color due to hydrated ferric oxide. However, this hypothesis is uncertain.

\subsection{Twin Burial and Gold Ornaments}

Apart from the non-local-red sand, Casal described two Sarcophagi; one is large, and another is small, from a Cist. The larger one had two legs on three rows (figure 2) and smaller one had two legs of two rows, in a Cist of yard ST-1. It is suggested that the two sarcophagi represented male and female interments. Casals questioned that it could be made after the practice of 'Sati22. However, no bones were recovered from these two sarcophagi to identify these as for male and female.

The date of these two sarcophagi is the same period, if so, the deaths occurred in same time. However, there is no conclusive evidence for the existence of male and female burials, although, two sarcophagi have been excavated in a yard. In addition, it is not strange that more than two burials were excavated from a Cist or from an Urn pit.

A hypothesis regarding the occurrence of two sarcophagi in a Cist is made after the study on antiquities that were found in the yard for clear understanding. The hypothesis is that burial was perhaps made after the death of a mother and a child.

- The larger Sarcophagus possibly made for the mother and the smaller one for the child.

- The occurrence of death of a mother and a child (during pregnancy) occurs more often that the death of Husband and wife.

- The grave goods from cist, are lid, vase, mirror and bells of bronze, the bracelets, ear rings, bangles, brooches, lotus leaf pendant with gold chain and beads of gold (Figure 4) and beads of silver and stone, all these grave goods belonged to female.

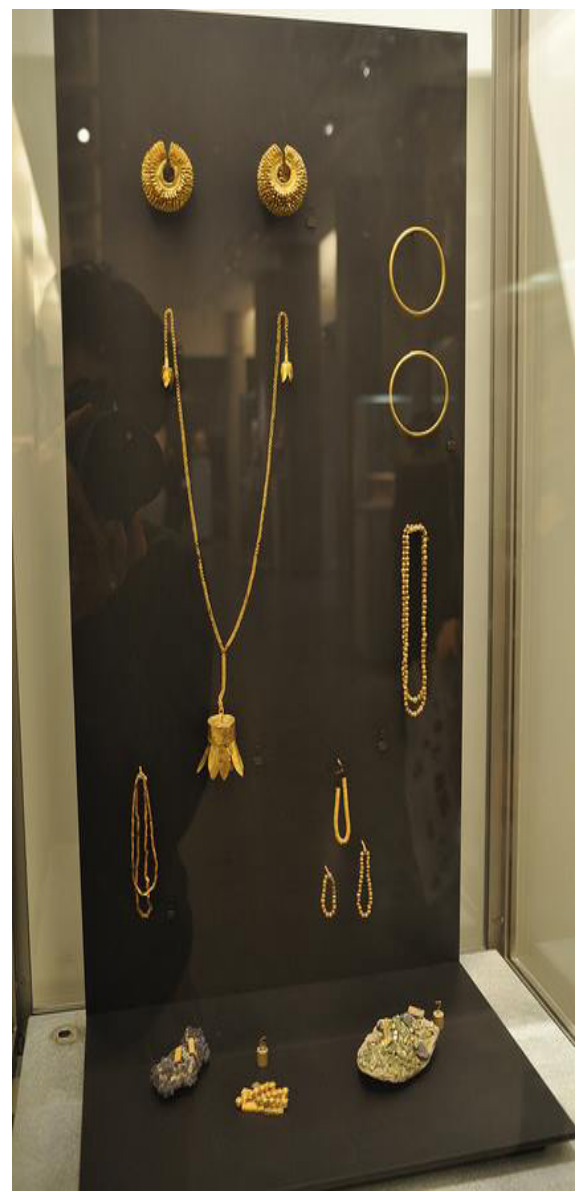

Figure 4. Gold Jewells from Suttukane Burials, Puducherry.

In one case, this cist could be belonging to a pregnant woman whose death might have occurred before or during the delivery. Hence, the objects found in the excavation belonged/offered to her. In modern times, if mother died with the child or the dead occur when the child was in the mother's womb; the dead body of the child is taken off from mother and cremated/buried separately.

On the other hand, the objects such as a wedge, a knife and a sword (not big one, like war sword, that usually found in the other burials) found in the same yard did not belong to the female. This could be placed as usual grave goods that generally found in other yards in the same period.

However, the golden treasure from this Cist is the indisputable witness to conclude the above conception of mother and child than the Husband and wife or a male and female.

Casal and Casal date the Suttukeni and Muttrapaleom group to the second - first century BCE period, which falls within the range of date for the Iron Age complex in the eastern Tamilnadu. If so, this cemetery group must have been contemporary to the early phase of Arikamedu. It is likely that there was some interaction between Suttukeni and Arikamedu during pre-periplus age. Not only the two sites are located along the same river system, but the art 
work assemblage from the Cist burial at Suttukeni seems to imply some foreign influence ${ }^{23}$.

Casal points out that the gold lotus-leaf pendent (Figure 5a and 5b) found in the Suttukeni grave, deposited with the Government of Puducherry ${ }^{24}$ and now with the Pondicherry Museum are similar to ornaments worn by a warrior, apparently of Iranian origin, depicted in a sculpture at Barhut. More important is the base of a bronze vessel, with concentric circles and central knob, found in their excavation ${ }^{25}$. Casal points out the parallel to the ceramic example of "knobbed" ware from Sisupalgarh excavation ${ }^{26}$. Ceramic and metal knobbed vessel bases are known in the Hellenistic - Roman world. The Sisupalgarh and Arikamedu examples are in local fabrics and must have produced regionally; perhaps inspired by Mediterranean proto-type as was the case with Rouletted ware and other pottery at Arikamedu ${ }^{27}$. The bronze example from Suttukeni may have been part of an imported vessel, although it is difficult to determine without studying the original antiquity in scientific approach. If Suttukeni had been part of an imported vessel, although it is difficult to determine some elements of western influence, logically the route of communication at that time would have been via Arikamedu.

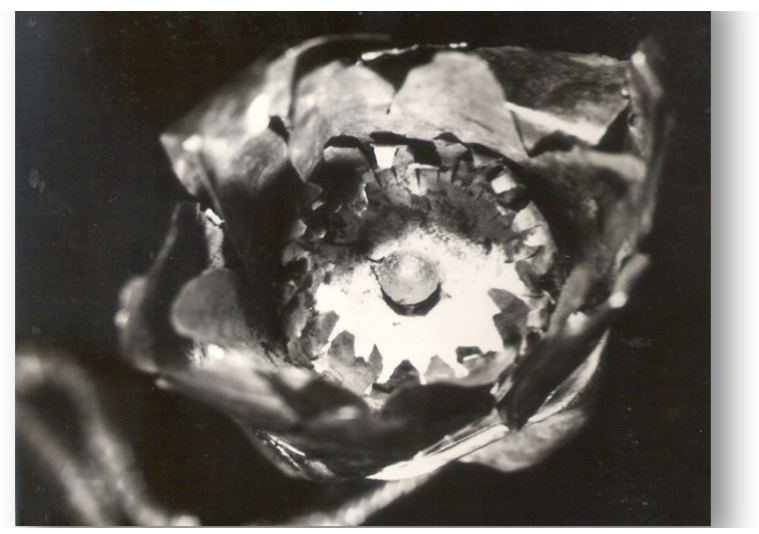

$5 \mathrm{a}$

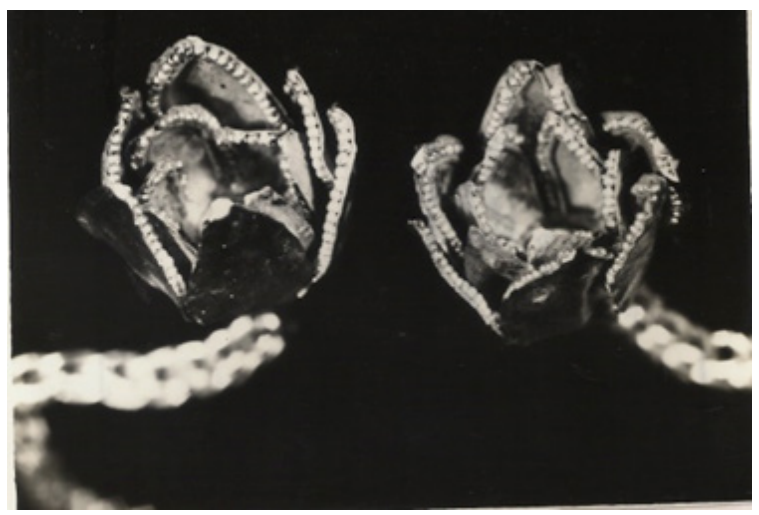

$5 b$

Figure 5 a and 5 b. The Gold Lotus-Leaf Pendent from Suttukane Burials.

\section{Auroville Burials and Cultural Link with Arikamedu}

Above sources seem not sufficient to understand the Iron Age culture in Puducherry during pre-Periplus time. Moreover, Iron Age burial sites, Suttukeni-Muttrapaleom are now disappeared. However, present study found many hundreds of Iron Age Burials both Urns and Sarcophagus sometimes with Cist or Cist slab at Auroville. In connection with early levels of Arikamedu the present study focused to excavate Iron Age burial sites to understand the life style, economy and role of proto historic Iron Age society in the emergence of early historic Port city Arikamedu.

\section{Excavations of Auroville Iron Age burials}

Archaeological importance of the site, perhaps, was first noticed by Mr. Poppo, an architect, from Germany residing at Auroville. He found hundreds of shreds and an Iron $\mathrm{axe}^{28}$. A carefully dug test-pit next to the slab revealed a complete six-legged sarcophagus measuring 120X90 $\mathrm{cm}$. The two pairs of horns of a ram in relief on as vault shaped lid as well on body. Since then, he informed it to Archaeological Survey of India, Madras circle.

An important contribution of Poppo's work at Auroville for Archaeology was the preparation of a site map and plotted the Cairn circles, Stone slabs, Urn burials and other archaeological remains that have been found on the surface. In early months of 1990, the Iron Age burials sites were properly surveyed.

In the year 2000, we found the Auroville is the only remaining sources to study the proto history and in connection with the rise of port city Arikamedu. The present study planned not to lose any Urns though they are in very deep and left with no traces on the surface. So we planned to make a grid excavation to locate the Iron Age burials. The top soil is removed about a meter to trace the locations of the Urn pits or granite slab or Cairn circle.

Totally 400 grids were excavated in this area and found 16 Urns. In this area we found only Urns in different size. No cairn circle found in this region. However, granite stone slab was used to seal some of the Urn pit. The grave goods such as ceramic, iron objects, beads and stone objects are found. Bonze/copper objects and ornaments are largely found in this area. Beads in general, stone and glass found competitively large in this region. Gold bead and lapis lazuli found here. All this shows, though this area is filled with urn burials the grave goods are very rich even it compare with the cairn circle burials. 


\section{Ceramic Types and Fabric}

In the ceramic assemble we understand some of the regional variations, which are reflected in the multitude of shapes and decorative features which have already studied by various scholars. In this study we found the distributions of some shapes of vessel types which are common among the burials found in Puducherry-Auroville region. However, almost all the ceramic found at Aurville is very brittle.

The black and red ware dominates in many types such as deep hemispherical incurving feature less rimed bowls some time small in size, dishes, and lids often with knobs. The upper part and the inner side of a black and red ware types always black, while the lower part is red. Due to the ill firing a yellowish orange colour division between black and red colour is visible on every black and red ware in Auroville. The red ware has been chosen mainly for large jars and small cup like lids. The black ware dominates ring stands, shallow bowls like dishes, lids and small cups.

A general characteristic of Iron Age ceramic wares is the highly polished, glossy surface, which evokes a metallic $\operatorname{look}^{29}$. At Arikamedu the Iron Age ceramic are like as in Begley observed character. She often compared the surface treatment with Perimbe burial Iron Age ceramics in Pondicherry Museum. The difference found only in metallic look between the Perimbe and Arikamedu Iron age ceramic. This difference perhaps, due to the burial ceramic are freshly made for the ritual purpose whereas in habitation sites like Arikamedu ceramic were in daily usage. The ceramic shapes such as Wheeler types 8 and 9 from Arikamedu are similar with the Aroville the black and red ware and black ware. The fabric compact and inclusion matrix are completely different from the Arikamedu habitation as well from the other burials of Puducherry region. This could be because that the grave ceramic was produced nearby for rituals purpose. The Auroville burial ceramic inclusions in the paste are mostly yellow whereas white from other burials in this region. The yellow inclusions are possibly from the locally available lime stone or ill firing. Graffiti marks on ceramic are found very less number.

\section{Metal Objects}

Metal objects like Iron, copper and gold are common metals found in Auroville Urn and sarcophagus burials. Occasionally gold beads found in Urns. Cups, lids mounted with bull, group birds and fish, Bangles and Ear rings are in copper. Iron was used for weapons both offensive and defensive.

The Iron implements form Auroville burials are representing that these people practiced Agricultural activities like cattle rearing, hunting and cutting trees for fire or to build houses.

Various types of copper objects found mostly in Urns. Bells, cups, lids sometimes mounted with molded bulls encircled with birds, hen, roster, peacock encircled with lily buds and fish (Figure 6a and b). Copper ornaments such as ear rings, beagles and ornaments for cattle like cow/bulls or ram. The copper figures mounting on the lids shows the people were practiced cattle rearing and hunting.

The copper images on the lid knob show the Auroville Iron age folk life style. Bull image encircled with a type of birds (Figure 6a) which even today migrating to this region. Iron Age folk frequently hunted this type of birds. Bulls, Hens and roster images are showing that they practiced cattle rearing and produced meat and egg to supply nearby developed Iron Age settlement at Arikamedu.

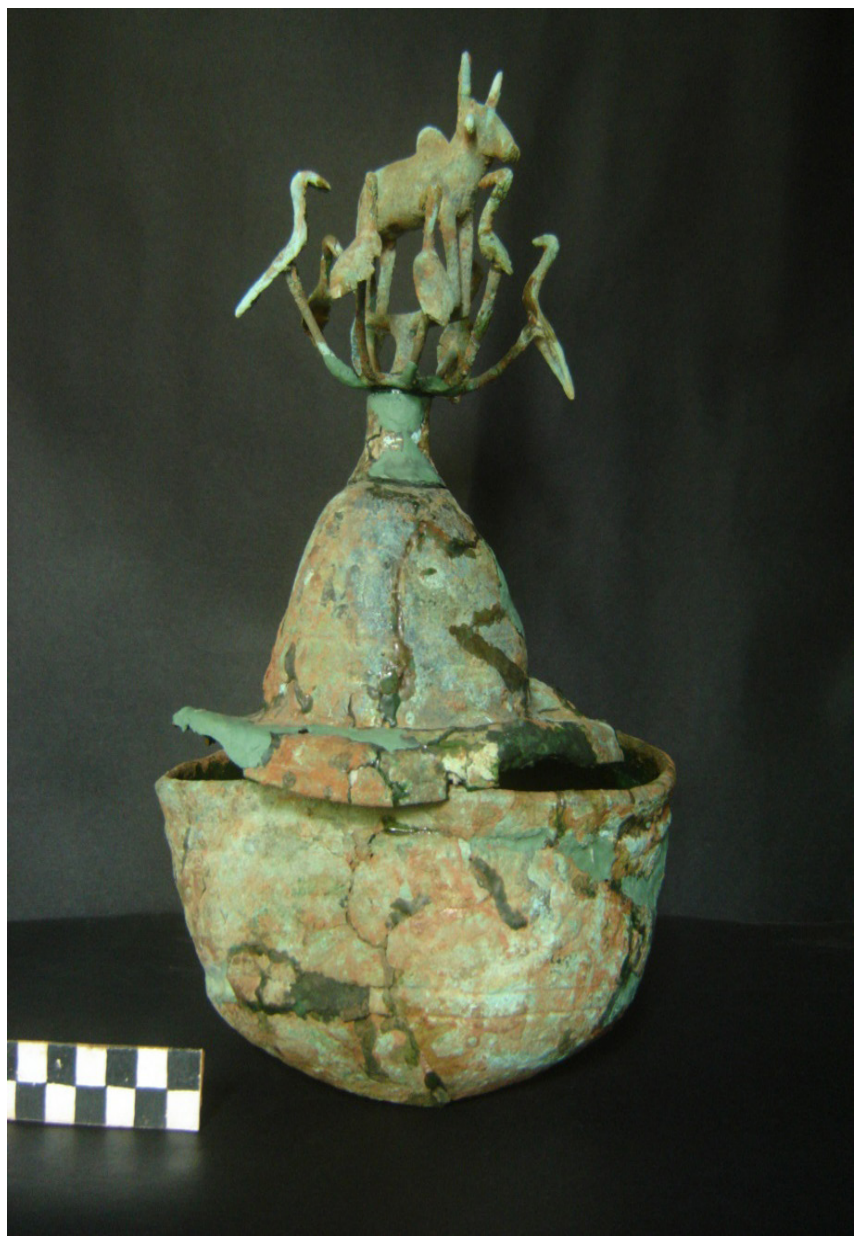




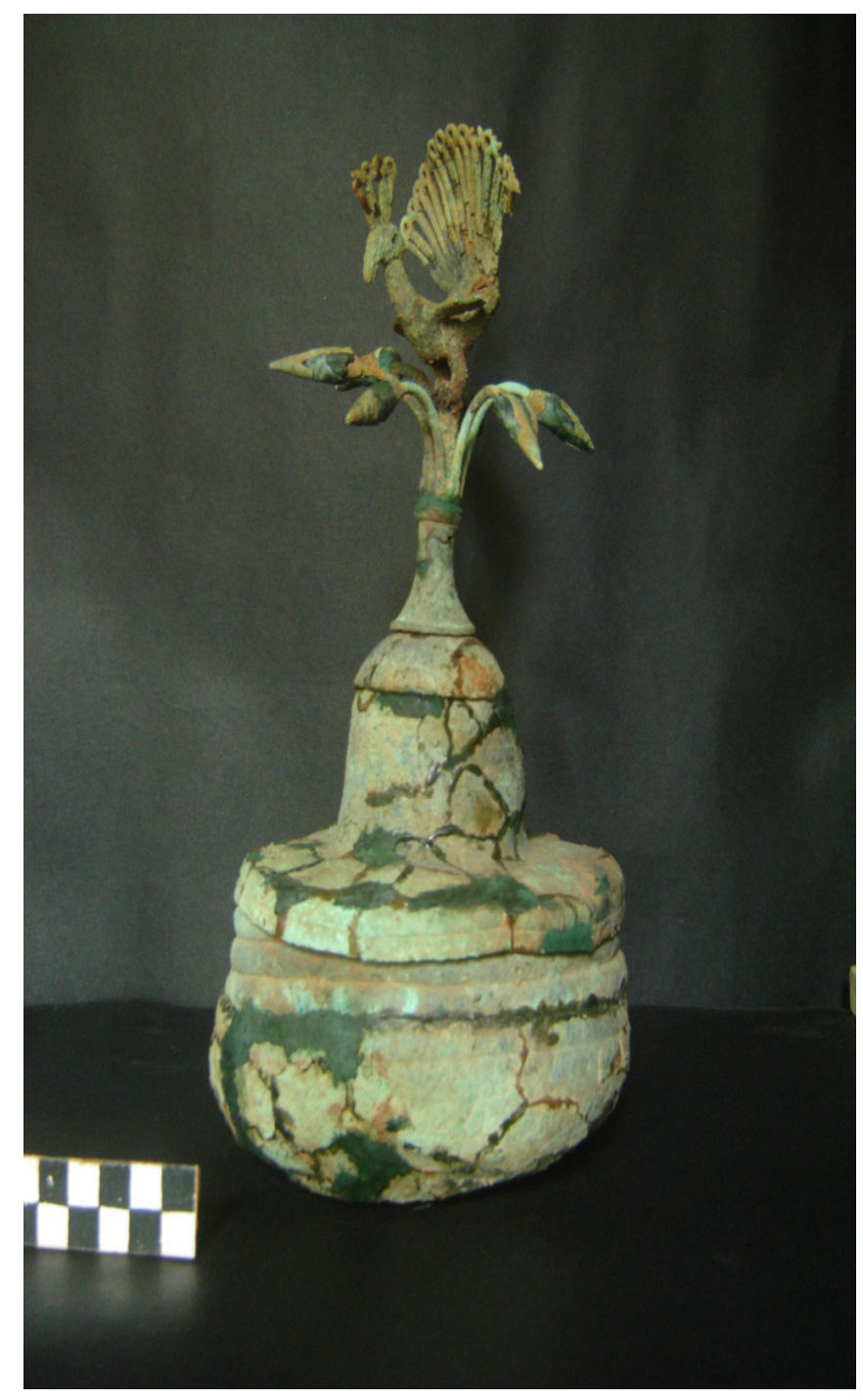

Figure 6. Copper Lid Mounted with a. Bull and b. Peacock, from Auroville Excavations.

Beads both glass and stone are found largely in the Auroville burials. Glass beads are non-translucent red, blue and black in colour. The non-translucent red glass beads are small with diameter of 2-4 mm whereas blue and black are micro in size. Stone beads are like carnelian, banded agate and etched carnelian. There is no trace of bead making industries around Aroville. Possibly these beads were imported from Arikamedu bead making place. However, etching work possibly done at Auroville. No etched carnelian beads found in Arikamedu shows that the etching work possibly done at Auroville before the burials ceremony. Beyond the stone and glass beads, we have Lapis Lazuli beads (Figure. 7) in various shapes. These beads were imported possibly through Arikamedu before the Roman trade phase.

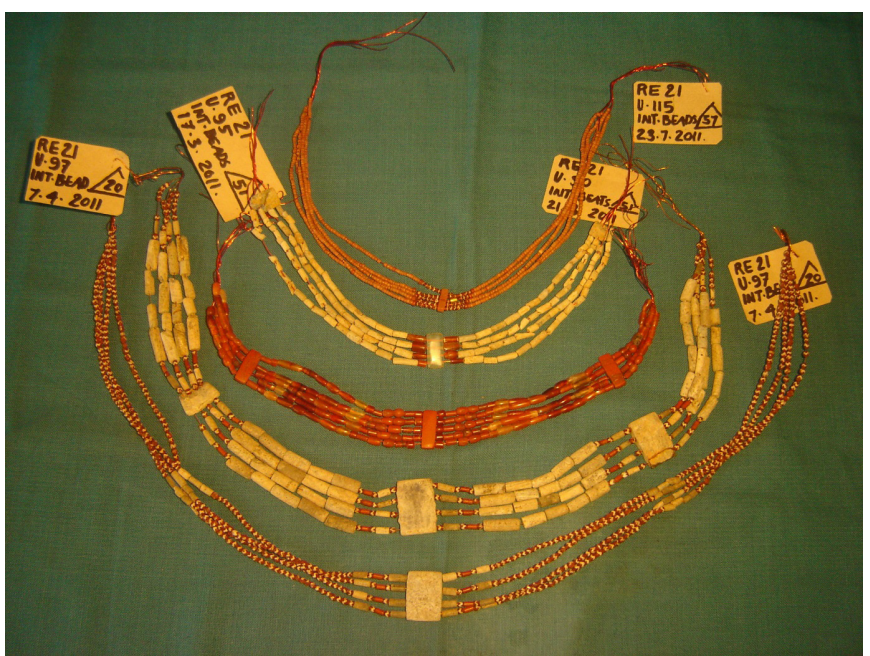

Figure 7. Stone, Gass and Lapis Lazuli Beads from Auroville Burials.

\section{Conclusion}

Iron Age folks settled in various places in Puducherry region whereas Arikamedu seems to be little urbanized. The Iron Age folk from Auroville location seem it be isolated from the Iron Age folk that they settled on the Gingee river bank. However, the isolated folk practiced trade locally and other occupation like hunting, agriculture, pottery making etc. In the ceramic comparative study the Auroville burial ceramic paste and inclusions are somehow different from the other burials located on Gingee bank.

Iron Age burials at Auroville, Suttukane-Muttrapaleom yielded a large variety of antiquities other than pottery such as iron objects and ornaments like beads of stones, gold and glass etc. Most important among the burial offerings are copper icons and lapis lazuli which are mainly giving the idea of their life style and their relation with Arikamedu preperiplus trade phase Iron Age habitation. Though the Auroville folk are isolated they had good relation with Arikamedu Iron age habitation who was busy with trade and industries before the arrival of Roman commodities. The Iron age folk helmeted various parts in Puducherry region who were practiced poultry the hens for eggs and rearing the cattle for meat, and milk which possibly consumed by Arikamedu Iron age settlers and keep them busy with external trade and industries to develop their settlement to Port city.

\section{References}

1. Casal JM, Casal G. Site Urbainet Sites Funéraires des Environs de Pondichéry. In his report Casals noted that those Faucheux's collections like pottery, a stone object and a bronze bracelet were neo-chalcolithic. Paris; 1956. 119-129. 
2. Leshnik LS. South Indian Megalithic Burials-The Pandukkal Complex. Wiesbaden; 1974.

3. Laffitte N. Reporte d'Ensembles Sur les Fouilles Exécutées dans le Sud de l'Inde. Paris; 1932.

4. Ravitchandirane P. Prehistoric Times of Pondicherry. HuSS: International Journal of Research in Humanities and Social Sciences. 2014; 1: 28-30.

5. Wheeler REM, Ghosh A, Deva K. Arikamedu: an IndoRoman Trading Station on the East Coast of India. Ancient India. 1946; 2: 17-125.

6. Casals identification on Fr. Faucheux collections like perforated black lid is commonly noticed in the modern pottery. Casal described this as a black surfaced handmade lid. Even in the modern days this type of lid is used to filter the cooked rice. In addition, the illustrated materials have been found on the surface and not from the excavation which is very hard to date without any comparative sample. A bronze bracelet with trumpet ends from Faucheux collections (Faucheux L. Une Vieille cite indienne près de Pondichéry Virampatanam. Pondicherry; 1945), illustrated by Casals does not at all fit into the known peninsular Neolithic assemblage. Hence, the Casals report on Fr. Faucheux collection is not sufficient to conclude that Gorimedu is a Neolithic assemble site. At present the study found no such evidence on the surface of Gorimedu and its vicinity. However, close to Gorimedu a village named Moratandi the study found some of proto historic artifacts and a terra cotta ring well on the surface. Mangalam is located near Villionur in Puducherry. A stone tool was identified as from the collections of Fr. Faucheux. However, only two illustrations were published without any description by Casals as neo-chalcolithic.

7. Pattabiramin PZ.Sites Archangéliques pré Historiques de Environs de Pondichéry. Revue Historique de l'Inde Française. 1948 ; (septième): 147-50.

8. Begley V. Sources of Pondicherry's History: Prehistoric to Early Historical Period. Revue Historique de Pondichéry. Pondicherry. 1987; 15: 1-20.

9. Indian Archaeological Review. 1984; 87: 77.

10. Pingel, P. “The Auroville Megaliths". The Indian Magazine of her People and Culture; 1987. 44-51.

11. Pattabiramin PZ. op. cit. 1948. 147-50.

12. Kuppuswamy. Fernel Urns of Bahour. Pondicherry: Revue Historique de la Pondichery; 1974-75 ; 12 :1-10.

13. Ravitchandirane P. Stratigraphy and Structural Context of Arikamedu in East and West. IsIAO.57: Italy; 2007. 223-24.

14. Dubreuil JG. Les ruines romaines de Pondichéry. Bulletin de l'Ecole Française d'Extrême-Orient XL. Paris; 1941; 2: 448-50.
15. Casal JM. Fouilles de Virampatnam - Arikamedu'. Paris; 1949.

16. The rouletted ware was first identified, named and dated in Arikamedu, then when the scholars are commonly using the term to describe or to date the early historical age sites. Begley V. Pottery from the Northern Sector. 1982-1992 in Begley $\mathrm{V}$ et al. The Ancient Port of Arikamedu: New excavations and Researches 1989-92. 1996. And also see Begley V. Chronology. Begley V et al. The Ancient Port of Arikamedu: New excavations and Researches 1989-92. 2004. II. EFEO. Pondicherry: 106-7. In some extent some scholars are relating rouletted ware sites with roman trade also (Ravitchandirane P. op. cit. 2007; 228-30).

17. Begley V. 1983. Arikamedu Reconsider. American Journal of Archaeology: 461-81. https://doi.org/10.2307/504104

18. Casal JM. op. cit. 1949; 31. And see also Begley V. op. cit. 1996; 14 for detail discussion.

19. Wheeler REM. Rome beyond its frontiers: London; 1954. 47.

20. Casal dated Arikamedu Iron Age (megalithic) levels as early 2nd century BCE. See Casal JM. ibid; 1949: 43. He excavated two Iron Age burial sites and dated those burials sites as early 2nd century BCE. See Casal JM, Casal G. Site Urbain et Site. op.cit. Paris; 1956. Recently we have excavated Iron Age burials at Auroville. We found the Burials in different types and different periods in Iron Age culture. On the basis of TL dating method the burials are dating between 500 BCE and 300 BCE. See Ravitchandirane P. Archaeological finds from Puducherry Region in Amaravathi. Chennai; 2017: 185-196.

21. Casal JM, Casal G. op. cit. 1956. see layer 8 in fig.15.

22. Casals raises the question whether the sati ritual might not be documented either in Muthrapaleaon or in Suttukeni. Ibid.

23. Begley V. op. cit.; 1983: 478.

24. Gabelé YR. La tombe mégalithique de Suttukeni. Nouvelles de Pondichéry II., 1958; 4. Reprint in Revue Historique de Pondichéry. Pondicherry; (1974-75) ; 12: 31-5.

25. Casal JM, Casal G. op. cit. 1956; plate-XXVI A.

26. Lal BB. Sisupalgarh 1948: An early Historical Fort in Eastern India. Ancient India. 1949; 5. plate-XLVI B.

27. Begley V. op. cit.; 1983: 469-71.

28. Pingel P. The Auroville Megaliths. The Indian Magazine op.cit. 1987 March: 44-51.

29. Begley V. Excavations of Iron Age Burials at Pomparippu, 1970'. Ancient Ceylon. 1981; 4: 85. 